\title{
Origins and Destinations: A Rejoinder
}

by

\author{
Renee Reichl Luthra, Department of Sociology, University of Essex \\ Thomas Soehl, Department of Sociology, McGill University \\ Roger Waldinger, Department of Sociology, UCLA
}

May 2019

In today's age of mass migration, the people crossing borders shape their own destinies, doing what neither home nor host state wants, seeking progress through movement. In both Europe and the United States, the immigrants' search for a better life has yielded an even more fateful result: the emergence of the "second generation," a population comprised of the immigrants' children, whether born in the society of immigration or brought there at a very young age from abroad. For the past quarter century, the question of how these "new" immigrant offspring will fare and why their trajectories might differ has attracted ever growing research attention while simultaneously generating continuing scholarly controversy.

Origins and Destinations: The Making of the Second Generation responds to this debate, building on a generation of scholarship and developing a new way of thinking about the problem at hand. We are gratified by the response that this new approach elicited from the distinguished scholars, all prominent contributors to the debate on both sides of the Atlantic, who commented on our book. We also extend our appreciation to the editors of Ethnic and Racial Studies for allowing our book to gain such attention and for giving us the opportunity to respond to our critics' insightful reactions.

\section{The International Perspective}

Theory is at once a way of seeing and not seeing; consequently, what researchers discover depends on the angle of vision taken at the point of departure. In Origins and Destinations, a book based on the responses from immigrant offspring surveyed in the New York and Los Angeles regions 
shortly before and after the turn of the millennium, we advocate for and adopt a perspective that takes into account the ways in which the inherently international nature of population movements across state borders yields effects well after migration has occurred. International migrations encompass sending and host societies, as well as the cross-border practices in which immigrants engage and the strategies that states use to control mobility across their borders. Consequently, in this book we looked for influences stemming from both "here" and "there", as opposed to the standard approach which has scholars metaphorically standing with their backs at the border, focusing uniquely on developments within the territory of the receiving state and ignoring the ways in which efforts to control migration continue to yield effects long after migration has occurred.

The international perspective to be encountered by readers of Origins and Destinations directs attention to variables that conventional approaches exclude. Emphasizing the international dimension reminds us that immigrant parents were socialized in the society of emigration, typically departing shortly before or during that moment in the life cycle when children are brought into the world. Hence, the lessons immigrant parents acquire in one context - the country of emigration -- are likely to soon thereafter be transmitted to children growing up in a very different context -- the country of immigration.

Thus, as noted by Jennifer van Hook, we proceed with a variable approach, understanding that countries of origin will vary along some continuum reflecting differences in the relevant messages received by immigrant parents during their own childhood. The value orientations identified by the World Values Survey provide us with tools for thinking about and measuring those home country influences that we designate with the concept of "context of emigration". We show that the context of emigration influences a variety of second-generation outcomes, over and above other national origin and individual level controls. For instance, the children of immigrants from countries with more secular orientations, where the average citizen places less importance on religious or traditional values, are 
more likely to obtain higher levels of schooling - even after controlling for the average levels of schooling of the immigrant group and the educational attainment of the child's own immigrant parents. Similarly, since migrant selectivity inevitably produces internationalized families - not everyone wants to migrate and not everyone who might want to migrate can do so - immigrant offspring grow up in kinship networks that are stretched across borders. Because those ties extend to significant others still living "there" and because households, even when separated by distance, often remain interdependent, these cross-border connections tend to exercise a continuing influence on lives that unfold in the society of immigration. For example, Origins and Destinations demonstrates that familial solidarity as enacted by parental sending of remittances, results in both higher educational attainment and higher levels of civic engagement among the children of immigrants in adulthood.

In developing and implementing the international perspective, we take great care to specify the appropriate level of analysis, the importance of which is illustrated by the example of remitting just given above. Taking the second generation's own remittance behaviors as our dependent variable, we find that the prevalence of remitting varied both among and within the groups represented in the surveys we analyzed. One might well expect that the frequency of remitting derives from orientations imported from place of origin, with background in a country where solidaristic orientations prevail making the sharing of resources with distant relatives more common; if so, the key influences stem from those operating at the level of the national origin group. But it might be the case that the more powerful motivation stems instead from the forces operating at the individual or household level: regardless of norms prevailing in the society of emigration, the immigrant offspring motivated to remit will be those most directly connected to close relatives still in the country of origin. Using multi-level analysis, a statistical technique that allows us to distinguish between group and individual-level influences, Origins and Destinations systematically answers questions of this sort: in this case, we see that neither context of emigration nor any of the other group level variables we assess affect second 
generation remitting. The key factor, rather, is the geographic configuration of the kinship network, with remitting most common among respondents with a parent still living abroad and least common among those who reported that all relatives had relocated to the United States.

\section{Methodological Innovations and Challenges}

Empirically implementing the International Perspective presented numerous challenges, as noted by our reviewers. In particular, any variable based approach using observational data raises the possibility of omitted variables and, as both Sin Yi Cheung and Jennifer van Hook rightly point out, there is a long list of potential variables that are likely to matter for one outcome or the other. As with most multi-level research the key constraint entails the limited number of group-level observations found in the sample. Even with the 67 national origin groups that we could extract from the pooled dataset, our sample was too small to include a large number of potentially relevant national origin level variables. More substantively, as a core aim of the book was to examine which arenas of second-generation life were the most influenced by national origin level influences, and which were most strongly determined by individual level characteristics alone, we also wanted to concentrate on only those few variables which we believed would exert an influence across a variety of domains. Given that recent writings, in particular the Asian American Achievement Paradox, have returned socio-cultural characteristics to the fore we chose to focus on the value orientation scales found in the World Values Survey.

Claudia Diehl's critique suggests a further reason to concentrate only on a few national origin level variables. Diehl emphasizes the importance of hypotheses that explicitly link national origin characteristics to second generation outcomes. We fully agree, and we point to several mechanisms linking the two world values survey scales to socioeconomic, political, and socio-cultural outcomes. We show, for instance, that whereas a scholarly culture of secular values operates to increase educational attainment directly, origins in a more cohesive and survival-oriented society improves educational attainment through the mechanism of enrolment in higher performing high schools; we also show that 
more cohesive and survival-oriented values result in higher naturalization rates via family-level decisions to obtain citizenship. While we unfortunately lack the bespoke data required to empirically test all of the mechanisms we posit, our ability to adequately discuss the mechanisms underlying the associations we observe would quickly be precluded were we to further expand the number of national origin variables under consideration.

A related issue concerns the relationship between individual and group-level variables. Filiz Garip suggests that we may have over-controlled: underestimating the effects of group level variables by including individual level variables that may have been located causally downstream from the group level variables. Claudia Diehl raises the opposite possibility: some of the associations linked to the context of emigration variables might have been weakened had we been able to control for these orientations at the individual level. To some extent these issues reflect different perspectives about whether to emphasize distal versus more proximal causes. In the case of the context of emigration, for example, we believe that the country level is the appropriate level on which to focus. We concede that we might have systematically presented results contrasting sparser models with estimates from models including more controls. While we conducted such analyses (and noted results where relevant) we decided against including all of them; as our book was already "drowning in data" as one of the referees of the initial manuscript rightly noted, we decided to pursue a more minimalist approach to presenting results. Overall, the approach we chose allows us to locate the level at which the driving forces for the outcomes we examine operate.

As Cheung notes in her review, one level of context that we did not extensively examine concerned neighborhood effects related to spatial segregation. Since school quality, strongly stratified at the local level, was one of the few outcomes associated with group level skin color, this points to the potential importance of unobserved racial segregation for the story we tell. Yet, since neighborhood choice itself is shaped by the individual and group-level variables we examine, including this additional 
layer could also run into problems of over-controlling. New York and Los Angeles, the cities where our respondents grew up, themselves are of course unique contexts and as Jennifer van Hook notes, examining how these processes play out in new destinations is a question for future research.

\section{Engagements with the canon: Segmented and neo-assimilation theories}

As our reviewers note, in Origins and Destinations, we build on and gratefully acknowledge our debt to the scholars who went before us - the authors whose published work stimulated our thinking and the researchers who indefatigably collected the data on which we relied. However, sincerely expressing appreciation doesn't imply agreement: this book takes a different direction precisely because it focuses so carefully on the level of analysis - an issue left unattended by the works that preceded ours.

Consider segmented assimilation: in contending that the diversity of assimilation trajectories comprised the novelty of the "new" second generation, segmented assimilation maintained that the fate of immigrant children would vary by differences in their parents' circumstances. Yet when considering the relevant parental conditions, the many writings associated with this perspective consistently conflate those operating at the intra-group level - human capital and family structure with those at the inter-group level - mode of incorporation. As Origins and Destinations notes, the central concept of mode of incorporation is never operationalized but rather proxied by national original groups. By insisting that "no matter how motivated and ambitious immigrants are their prospects will be dim if government officials persecute them, natives consistently discriminate against them, and their own community has only minimum resources to offer," the authors of Legacies, the central segmented assimilation text, also maintained that the explanatory value of group-level factors would trump those associated with family and individual level resources. Yet lacking a framework that could disentangle processes operating at both levels, Legacies could never evaluate the hypothesis that its authors advanced. 
Origins and Destinations puts precisely that idea to a test. We show that only one group level characteristic - the mean level of education of the national origin group in the local area - affected the transmission of parents' education to their children's schooling attainment, boosting schooling among respondents who belonged to more educated national origin groups. By contrast, having immigrant parents from more advantaged contexts of immigration and emigration strengthened the impact of children's own education on their occupational attainment. However, we also demonstrate that the influence of these very same group-level factors - so central to the segmented assimilation framework paled in contrast to those operating at the individual and family level.

The segmented assimilation framework also posits that assimilation will yield outcomes both good and bad, an idea surfacing in Legacies via the argument that different acculturation strategies consonant, dissonant, or selective - would mold children's outcomes. Yet as noted by Diehl and Van Hook, we find no evidence that parental choice of household language - a key acculturation variable has any direct net impact on educational or occupational attainment. Rather, we show that an acculturation strategy that reinforces family or ethnic cohesion will prove protective when a disadvantaged group context might otherwise sap familial resources: among the Los Angeles respondents, ethnic supplementary education only made a significant difference for the relatively small number of children of low-skilled, mainly Latino immigrant parents who used this option and not to anyone else. This observation - running counter to much of the empirical work inspired by segmented assimilation which spotlights ethnic mobility strategies among Asian populations - could only emerge because the approach taken in Origins and Destinations allowed us to separate parents' and group-level characteristics.

As Claudia Diehl notes, our findings leave us doubtful about segmented assimilation. That skepticism does not, however, imply endorsement of the main alternative - the "new assimilation theory" introduced by Richard Alba and Victor Nee in the early 2000s. 
As we argue in Origins and Destinations, the strength of this approach comes from its simplicity: since immigrants are compelled to adapt to a new environment and adaptation generates the competencies that reduce the costs of strangeness, immigrants and their descendants come to resemble those around them. And thus, immigrants' own survival strategies inevitably lead to assimilation, whether wanted or not. Yet, by focusing uniquely on the social processes whereby immigrants became like the others around them and were so accepted, assimilation theory, both new and old, neglects the fundamentally political sources of civic stratification among persons who enter a new territory as aliens, differing in rights and entitlements.

Migration to the developed world is good for migrants from the developing world; however, the countries of the developed world keep those options limited, with policies shaped by the need to maintain the people flows required by a globalized economy without upsetting negative popular views of immigration. As we argue in Origins and Destinations, the effort to reconcile those pressures yields a system of civic stratification: newcomers get sorted into different positions, each with a distinctive set of entitlements, depending on the legal circumstances of into the new environment. These differences in entitlements, which in turn lead to differences in naturalization rates and access to the full benefits of membership in the policy, have real consequences. Origins and Destinations shows that the 1.5 generation non-citizens attained lower levels of schooling and occupations of lesser status than their naturalized citizen counterparts, net of other variables, including group-level prevalence of legal statuses. For these 1.5 generation respondents, citizenship provided the channel connecting uponarrival status to educational and occupational attainment: those who arrived on a temporary visa or without authorization experienced a far longer trajectory to citizenship than their counterparts who possessed a green card when crossing U.S. boundaries. The book further demonstrates that factors affecting access to citizenship influence its exercise, as the experience of prior or current exclusion from the polity impeded engagement in public-oriented activities for which citizenship was no prerequisite. 
Thus, in the language of statistics, the variation in legal statuses comprise omitted variables, which is why straightforward application of assimilation theory, whether updated or old-fashioned, is likely to produce biased results.

\section{Looking towards the future}

As noted by Jennifer Van Hook, the salience of boundaries, legal status included, will vary across time and place: our analysis rests on surveys of immigrant offspring whose presence reflects the revival of mass immigration to the United States, as the $20^{\text {th }}$ century neared its end. In retrospect, this was an era of kinder, gentler migration control, marked by the end of the national origins system; a commitment to refugee resettlement - albeit under the influence of political considerations deeply at variance with the Geneva convention; policies that facilitated both the arrival of a growing number of foreign students and their subsequent transition into the ranks of successful professionals; and tolerance for a contradiction between de jure and de facto immigration policies, the first banning undocumented immigrants, the second allowing workers without papers to readily access jobs from which they were technically forbidden. And then in 1986, legislation opened the gates to legal permanent residence, leading next to reunification with immediate family members left behind, and later, to the acquisition of U.S. citizenship. Thus, for the large majority of immigrant offspring whom we studied, separated families and unauthorized status were transient phenomena from which release was found relatively early in life.

But that was then, this is now. For many, though certainly not all, of the immigrant offspring coming of age as we write, the United States remains a wanted, but much less welcoming destination, dominated by a turn in migration policy that has made unauthorized status an enduring trait, has left U.S.-born children of undocumented immigrants from Asia, Europe and Latin America fearing the imminence of a parent's departure, and has driven half a million U.S. citizen children to be schooled in Mexico, thanks to the deportation and self-deportation of their parents. With physical dislocation from 
loved ones and lasting legal marginalization both more likely now, the impacts generated by crossborder connections and civic stratification, as shown in Origins and Destinations, are likely to be lower bound estimates of these influences going forward. Therefore, an International Perspective is even more necessary to the next wave of second-generation research emerging today. 